\title{
Veera Gnaneswar Gude (Ed): Green Chemistry for Sustainable Biofuel Production
}

Ken Jones ${ }^{1}$

(c) Springer-Verlag GmbH Germany, part of Springer Nature 2018 predicted cost of production. In over two decades of reviewing books on biofuels, not a single paper has ever provided such data. Until they do, most readers will remain unconvinced that these synthetic fuels have any practical future.

Of the processes described, possibly those utilizing feedstocks of negative value, defined as those whose disposal cost can be deducted from the product's eventual manufacturing cost, have a future. Globally, billions of gallons of wastewaters are processed daily, mostly adopting the activated sludge process, in turn producing sewage sludge. The USA alone disposes of 8.2 million tons per annum of sewage sludge, by incineration, landfill or as compost. All have negative value. Several routes of conversion into biodiesel are proposed; transesterification; hydrotreatment; gasification and others-but are any of these routes cost competitive? It can only be assumed from the total silence on this subject that the answer is negative. More ominously, it would appear we are not meant to know.

It is in the nature of humankind to seek the most economic answer to any given problem. Currently, that is the burning of fossil fuel. However, most governments tinker with subsidies, when they run out of taxpayer's money, commonsense has to return, or until such time as the new technologies are shown to compete on price. The major oil companies have declared they can still prosper at a crude price of $\$ 50 / \mathrm{bbl}$. Using that as a benchmark, and by publishing the estimated costs of production of the new technologies described here, it would then be possible to assess the real value of the various approaches investigated. Although one can admire the ingenuity in some approaches, the actual value of the work is ephemeral.

Ken Jones

chromatographia@springer.com

1 Knutsford, UK 